difference in their lineage is the treatment of one with DNA containing large rather than small numbers of DHFR genes.

It turned out that after 30 days, the proportion of marrow cells derived from the DHFR-gene treated marrow culture was greater than $70 \%$ in most cases. The proportion continues high as long as methotrexate is administered, but when it is withdrawn the ratio returns to normal. Since the increase was also found in stem cells, this result is puzzling unless one assumes that the DHFR genes are gradually eliminated from the cell population when selection is removed. It is not yet known whether the DHFR genes have become integrated into the cellular DNA; if they are persisting in an episomal state they may be more easily lost. The mice were apparently healthy, as the levels of methorexate used for selection were not very high. Direct analysis of the marrow cells showed a high level of the enzyme, as would be expected.

One cogent objection that could be raised to this work is that as genes for DHFR do exist in normal marrow cells, it is possible that the resistant cells could have arisen in the treated cells by the amplification of these DHFR genes rather than by the introduction of genes in vitro. Indirect supporting evidence that their procedure does lead to transformation and selection of transformed bone marrow cells is provided by other experiments by the same authors (submitted for publication elsewhere) in which cloned herpes TK gene sequences were inserted into mouse marrow cell cultures and these cells were transplanted into irradiated mice of a different chromosome pattern, but otherwise genetically compatible. Unlike the mouse DHFR genes, these herpes TK genes can be unambiguously recognised by their DNA restriction pattern as they are from a human virus and do not normally occur in mouse cell nuclear DNA.

The transplanted marrow did indeed contain herpes TK genes, and these appeared to be integrated in some fashion into the host cell DNA. Moreover, if the mice are treated with methotrexate (which also can select for thymidine kinase by another mechanism) the cells containing the gene are selected for in the marrow.

Bone marrow is at present the only tissue in which one might seriously consider clinical gene replacement in the near future, to correct some of the haemoglobinopathies, for example sicklecell anaemia. Bone marrow can be relatively easily extracted, manipulated in vitro and replaced.

However we do not yet have the answer to the crucial question of whether it will be possible to restore correct control over the introduced genes, for it is absolutely essential that they should be expressed under the same controls as tirose in normal animals. Expression in inappropriate tissue or abnormal control in the cell in which they are normally expressed could be disastrous. A surplus of one globin chain would be as harmful physiologically as a deficit, substituting an iatrogenic illness for a genetic one. Before gene therapy becomes a real possibility either ways must be found to insert the required gene into the 'correct' place on the chromosome or other methods

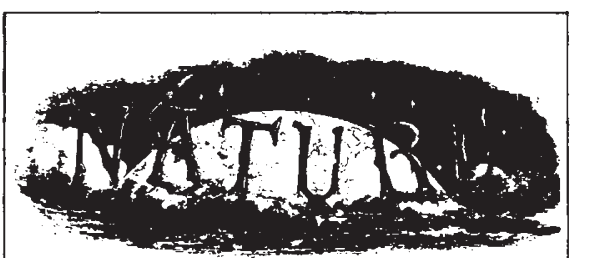

100 years ago

The Photographic News is responsible for the following:- Everybody knows how jealously the gates of the Royal Observatory are guarded, and what difficulties even scientific men have to gain admission. But $\mathrm{Mr}$. Glaisher, the worthy President of the Photographic Society, and who was until lately Superintendent of the Meteorological Department, tells a story that goes far to prove that nothing is impossible to a resolute man. A vast star shower had been anticipated and its coming heralded in every newspaper. The staff at Greenwich, with the AstronomerRoyal at their head, remained the whole night through making observations and counting the bright meteors as they fell. The weary night passed, and the small hours of the morning came, only to find the jaded observers still pursuing their duty. "'That makes 10,704," said our friend Mr. Glaisher. "Beg pardon; how many?" exclaimed a voice behind him. " 10,704, ," repeated the President of the Photographic Society; and then, not recognising the voice, he turned and saw a stranger: "Who are you, and where do you come from?" At first, the only possible conjecture was that the stranger had fallen from the clouds along with the star shower; but it was not so, for, closing a little note-book, he simply replied, "I am the special correspondent of the New York Herald. Thank you very much. Good morning." How that special managed to get through the park gates and elude the vigilance of the keepers; how he got inside the walls of the Observatory; how he pressed into the sanctum of the Astronomer-Royal is a mystery to this day; but within a few hours of his interview with Mr. Glaisher the readers of the New York Herald printed a correct account of the marvellous star shower, together with many interesting details of the Observatory itself.

The French Exploring Expedition for the Trans-Saharan Railway has left Wargla for the interior of Africa.

From Nature 21; April 1, 524; 1880. must be found to ensure balanced gene expression.

The final question is, why bother, particularly as antenatal diagnosis is now possible for sickle cell disease and thalasaaemia? But there are still many people suffering from these diseases, and there will always be some new ones arising - this in itself justifies the approach. However, the main reason is perhaps that the haemoglobinopathies are quite unusual amongst genetic disease in that carriers can be identified easily. There are many conditions where carriers cannot be detected antenatally, and in this case treatment rather than prevention may be the only feasible strategy.

\section{Winds in the polar thermosphere}

\section{from Henry Rishbeth}

THE observations of Smith and Sweeney, reported in this issue of Nature, page 437 make a new contribution to knowledge of the polar upper atmosphere - specifically the thermosphere, at heights of 200-300 $\mathrm{km}$. Working in Spitzbergen, during continuous winter darkness, Smith and Sweeney used a Fabry-Perot interferometer to measure doppler shifts of the red $630 \mathrm{~nm}$ auroral emission. The instrument points sequentially in different directions and, with a few minutes' integration, typically measures the wind component in the line of sight to within about $\pm 20 \mathrm{~m} \mathrm{~s}^{-1}$.

The $630 \mathrm{~nm}\left({ }^{3} \mathrm{P}-{ }^{1} \mathrm{D}\right)$ emission is radiated by the metastable ${ }^{1} \mathrm{D}$ state of atomic oxygen, which is excited by dissociative recombination of $\mathrm{O}_{2}{ }^{+}$ions or by soft electron precipitation. With a radiative lifetime of $110 \mathrm{~s}$, the ${ }^{1} \mathrm{D}$ atoms may be expected to take up the neutral air velocity so that the doppler shift of their radiation should correspond to the neutral air wind velocity. The technique is now wellestablished for measurements of nighttime thermospheric winds at midlatitudes $^{1,2}$; more recently the Mawson Institute group in Australia has reported daytime measurements of thermospheric winds with the technique, obtained despite the intense background of scattered solar radiation ${ }^{3}$.

This optical technique has the drawback that the radiation originates over a range of height, within which the wind velocity may vary considerably. This problem may be real for the thermally-driven winds at lower latitudes; but in the polar thermosphere (as discussed later) the wind is mainly driven by a large-scale electric field which is almost height-independent above $200 \mathrm{~km}$,

Henry Rishbeth is at the Appleton Laboratory, Slough. 